NASA Technical Memorandum 85920

NASA-TM-85920

19850007378

\title{
Ground-Effect Analysis of a Jet Transport Airplane
}

\section{Robert E. Curry and Albion H. Bowers}


-

$\because$ 
NASA Technical Memorandum 85920

\section{Ground-Effect Analysis of a Jet Transport Airplane}

Robert E. Curry and Albion $\mathrm{H}$. Bowers

Ames Research Center, Dryden Flight Research Facility, Edwards, California

\section{N/Sก}

National Aeronautics and

Space Administration

Ames Research Center

Dryden Flight Research Facility

Edwards, California 93523 


\author{
Robert E. Curry ${ }^{\star}$ and Albion H. Bowers ${ }^{\dagger}$ \\ NASA Ames Research Center \\ Dryden Flight Research Facility \\ Edwards, California
}

\section{Abstract}

An analysis of the ground effect of a jet transport airplane has been made. Data were obtained from recent flight tests primarily using the constant angle-of-attack approach technique. Reasonable results were obtained for ground-effect pitching moment and lift increments. These were compared with data from other sources, including computations, wind tunnel, and previous flight tests. A recommended ground-effect model was developed from the results. A brief simulator study was conducted to determine the sensitivity of a particular configuration to this ground-effect model and its associated uncertainty.

\section{Introduction}

Aerodynamic ground effect is known to be a significant factor to flight mechanics at low altitudes. Considerable uncertainty is associated with most predictions and measurements of this phenomena. This is partly because of the difficulty of determining forces and moments that are small with respect to the total vehicle aerodynamics. Wind tunnel predictions are usually complicated by the need to simulate a ground plane without boundary layer and engine thrust. Flight testing is limited because of the difficulty of performing maneuvers in close proximity to the ground. The perturbation of conventional air data sensors caused by ground effect must also be considered in designing flight tests. Furthermore, even small gusts and turbulence that are encountered at low altitudes can have effects on the same order of magnitude as ground effect.

For most applications, modeling of ground effect for simulation or other analyses is generally not a critical requirement. These effects are typically beneficial in flaring out an aircraft's approach path for landing and have been described as a "ground cushion." 1

A high-quality model of ground effect is required in support of the controlled impact demonstration (CID) project conducted by the National Aeronautics and space Administration (NASA) and the Federal Aviation Administration (FAA). This deliberate impact of a full-scale jet transport will be used to demonstrate an antimisting fuel additive, seat restraints, and other crash safety features. Structural response data will also be acquired for analysis purposes. The aircraft, a Boeing -720 airlinex, is modified with a ground-based piloted control system so it can be remotely manuevexed to the intended impact location. To meet the test objectives, it will be necessary to control the flight conditions with great precision up to the

\footnotetext{
* Aerospace Engineer. Member AIAA.

tAerospace Engineer.
}

This paper is declared a work of the U.S. Government and therefore is in the public domain. point of impact. Early simulation has shown that ground effect will significantly alter the flightpath, and the pilot will have little chance to compensate for this deviation because of slow response of the remote control system. Also, the approach to impact involves a high rate of descent, which reduces the time available to the pilot to make flightpath corrections.

In support of this project, an effort was made to determine the best ground-effect model possible. Flight tests using a similar aircraft, as well as the actual CID airplane, were conducted. A literature search was made for previously obtained data and analytical techniques. A comparison of these collected data was made and a recommended model with uncertainty bounds was determined. A groundbased simulator was used to predict airplane response to ground effect and the sensitivity to the associated uncertainty.

\section{Flight Testing}

\section{Aircraft}

Two vehicles were flight tested as part of this study. Initial results were obtained with a $\mathrm{KC}-135$ tanker aircraft. This was followed by flight testing with the Boeing-720 aircraft that will be used in the CID project (referred to in this paper as the CID/720). The CID/720 airplane is shown in Fig. 1 .

The KC-135 aircraft aerodynamic configuration is nearly identical to the CID/720. Equipment for in-flight refueling, a modified nose shape, and a slight difference in tail length are the only noticeable external variations, and these differences were considered negligible.

Instrumentation

Instrumentation consisted of both onboard and ground-referenced data systems.

The KC-135 aircraft had an onboard analog system that provided a continuous hard-copy trace of elevator position data. Measurements of angle of attack from a fuselage-mounted vane and radar altimeter were displayed to the pilot; however, these were not used for postflight data reduction.

The CID/720 onboard data were obtained through a pulse code modulation (PCM) system and were transmitted to a ground station for postflight processing. Parameters used in this study include elevator and stabilizer position, radar altimeter, thrust lever position, and flap position. Again, an angle-of-attack vane was mounted on the side of the fuselage for use by the pilot during maneuvers.

For both the KC-135 and the CID/720 aircraft, weight and center of gravity were computed from fuel readings made by the flight crew and from the measured empty weight. 
The aircraft were optically tracked during the maneuvers by the Air Force Flight Test Center (AFFTC) Askania cine-theodolite system. 2. This facility obtained photographs from two calibrated camera locations at a rate of 4 frames per sec. The film was interpreted for a measurement of airplane position with respect to the ground as a function of time. Flightpath angles, velocities, and accelerations were then extracted computationally, By determining the relative position of the nose and tail of the airplane for each photographic frame, an estimate of pitch attitude is possible. Angle of attack can then be computed from the flightpath and pitch angles. The benefit of this system for ground-effect analysis is that it does not rely on pressure data or vane position data that may be perturbed by ground effect. For the KC-135 aircraft analysis, altitude above ground was also computed from the Askania data by subtracting the airplane position from a model of the ground plane. Because the Askania data is based on photographs, the precision of the results increases as the airplane approaches the camera location near the runway.

\section{Flight Maneuvers}

Flight maneuvers consisted of both constant angle-of-attack approaches and level passes over the runway. Two flights of the KC-135 aircraft were made, resulting in 11 approaches and five passes. Six constant angle-of-attack approaches were made with the. CID/720 during one flight.

During each approach the pilot trimmed the airplane on a shallow stabilized glideslope prior to entering ground effect. The airspeed for each run was selected, based on current weight, to obtain a given lift coefficient. The flap position, power setting, and stabilizer trim position were only adjusted above an altitude of about $90 \mathrm{~m}$ (300 ft) above ground. The landing gear was extended throughout the manuevers. As the airplane responded to ground effect the pilot attempted to maintain constant angle of attack with elevator control input only. Variations in the flightpath were attributed to the additional forces present in ground effect. The pitching moment increment in ground effect was determined based on the amount of elevator trim required. By maintaining constant angle of attack, the glideslope was reduced in ground effect and generally resulted in smooth landings. For some runs this resulted in the airplane flaring to level flight without touching the ground. The airplane was tracked by the Askania system as it descended from an altitude of about $90 \mathrm{~m}(300 \mathrm{ft})$ to its lowest point. Onboard data were merged with the postflight processed Askania data and were analyzed using a FORTRAN computer program. The constant angle-of-attack technique is discussed in greater detail in Refs. 3 and 4. using out-of-ground-effect wind tunnel data, and the Askania measurement of angle of attack, the results were corrected for variations in angle of attack. Ground-effect lift increments were corrected for elevator input so that untrimmed increments could be computed. The change in engine thrust because of angle-of-attack variation was not accounted for and represents a large source of uncertainty in the drag measurements.
Several level passes over the runway were made with the $\mathrm{KC}-135$ aircraft to measure changes in trim caused by ground effect. This technique was less successful and used test time less efficiently than the constant angle-of-attack approaches. Passes were made at altitudes of $60 \mathrm{~m}(200 \mathrm{ft})$, which were out-of-ground-effect, and at lower altitudes. since a go-around was made between each pass, consistent power settings and wind conditions could not be assumed for all passes. This technique was abandoned after the first $\mathrm{KC}-135$ aircraft flight in favor of the constant angle-of-attack method.

\section{Literature Search}

A literature search was made to locate existIng data and prediction techniques that could be applied to the CID ground-effect analysis. Results from four sources are discussed in this report and are compared with the current flight results. When appropriate, the data were adjusted for common comparison with the CID/720 configuration. Pertinent geometric characteristics for the various configurations are shown in Table 1 .

\section{Original predictions}

This model was documented by the Boeing Airplane company for use in developing flight simulators, 5 and is believed to be based on wind-tunnel tests with a fixed-ground plane. The test techniques for this model represented the state-of-theart in the 1950s, but are not representative of the current improved capabilities of Boeing.

\section{DATCOM}

The semiempirical DATCOM analysis technique was used to estimate the ground-effect model as a function of angle of attack and altitude above the ground. As described in Ref. 6 , the ground-effect analysis is known to be approximate, at best. The fuselage and wing thickness are neglected. The factors that account for the bound vortex and flap effects include considerable uncertainty. Some data required for the DATCOM calculation, specifically the lift curve slopes for the wing alone and tail alone were computed using the wing-body panel theory. 7 Some component wind tunnel data (out-ofground-effect), 8 were also used. Calculations were made for a $45^{\circ}$ flap position and adjusted to other positions.

\section{Wind Tunnel}

Wind tunnel tests of a 0.068 -scale model based on the Boeing 367-80 (Boeing-707 prototype) in ground effect are discussed in Ref. 9. The tests were run primarily to investigate the benefits of flap blowing for boundary layer control; however, baseline results without blowing were also obtained. Thrust on the inboard engines was simulated for some of the runs using compressed air, and a moving-ground plane was installed for all of the tests. A leading-edge slat and plain flaps (not representative of the CID/720) were installed for all runs. No adjustments to the data were made for these deviations.

In most cases, data taken as a function of altitude did not reflect a reasonable trend. 
The bulk of the data was obtained at $60^{\circ}$ flap, although some limited data were available to extrapolate the results to other flap settings. An adjustment was made to the pitching. moment data because of the difference in tail length of the wind tunnel model and the CID/720.

\section{Convair 990 Flight Tests}

Some limited ground-effect flight data were obtained using a Convair 990 aircraft; these are discussed briefly in Ref. 1. The Convair 990 is a four-engine transport aircraft with external geometry similar to the CID/720. Differences that are expected to be most pertinent with respect to the ground effect are flap geometry and aspect ratio. The data were obtained at a flap position of $50^{\circ}$ and at lift coefficients near 1.0. No adjustments for flap position or geometry were made to these data.

\section{Simulator Testing}

The recommended ground-effect model was implemented in a ground-based simulator of the CID/720 configuration. The simulator represents the airplane as it is operated through the remote (groundbased) control system. An autothrottle was used for all runs to attempt to maintain airspeed. Control surfaces could be actuated from onboard feedback loops as well as the remote cockpit. For some of these tests, remote cockpit inputs were supplied by an autotracking system that adjusts the controls in an attempt to follow a programmed flightpath to impact (similar to the CID impact profile). This provided comparable results from run to run so that response to ground effect alone could be isolated.

The simulator operation was initiated with flight conditions of approximately $5.2 \mathrm{~m} / \mathrm{sec}$ $(17 \mathrm{ft} / \mathrm{sec})$ vertical sink rate and $78 \mathrm{~m} / \mathrm{sec}$ (256 ft/sec) airspeed at an altitude above the ground-effect model. A flap postion of $40^{\circ}$ was used, which resulted in a pitch attitude of about $1.5^{\circ}$. As the simulated flightpath responded to the ground-effect model, the change in these flight parameters was recorded.

\section{Discussion of Results}

\section{Ground-Effect Data}

Flight results obtained from the $\mathrm{KC}-135$ aircraft testing consisted primarily of the groundeffect pitching moment increments. It was noted in the postflight analysis that atmospheric turbulence had a significant effect on the flightpath during the manuevers. Although flightpath deviations caused by turbulence greatly distorted the lift and drag measurements, reasonable pitching moment trends were obtained. An example of the groundeffect pitching moment increment is shown in Fig. 2. Data were obtained for flap positions of $30^{\circ}$ and $50^{\circ}$, but did not identify any trend caused by flap position. Also shown on Fig. 2 is an incremental measurement of ground effect from the level pass maneuvers. Although the comparison is reasonable, it is clear that the constant angle-of-attack approaches provide more useful data. Nearly all of the CID/720 manuevers provided reasonable pitching moment results.
Lift increment measurements from the CID $/ 720$ flight were more successful because of better atmospheric conditions. Examples of dive angle (instantaneous angle between the flightpath and horizon, positive for descending flight) profiles for several approaches are shown in Fig. 3. It is suspected that unsteady winds caused the initial glideslope to vary on some runs at all altitudes, such as in Fig. $3(a)$, and the effect of gusts can be seen in data of Fig. 3(b). Although the magnitude of these deviations may appear small, the resulting lift increment calculations are difficult to interpret. For this reason, only a few runs, such as the one shown in Fig. 3(c), generated good lift increment values. Examples of the measured lift increments in ground effect from two successful runs are shown in Fig. 4.

The variation of angle of attack for several runs is shown in Fig. 5. It can be seen that the Askania-measured angle of attack consistently decreased in these runs as the airplane approached the ground. This led to the conclusion that the pilot's indicated angle of attack was influenced by the ground. As a result, relatively large corrections were necessary to compensate for these angleof-attack variations.

An example of the drag increment data is shown in Fig. 6. As expected, a negative trend with decreasing altitude is evident; however, the scatter in the data is too great for modeling purposes. The drag calculations are sensitive to the longitudinal acceleration measurement which is of relatively poor quality. As previously mentioned, deviations in angle of attack may alter engine thrust, a factor that was not accounted for in the drag calculation.

Data in the form of Figs. 2 and 4 were extrapolated to determine pitching moment and lift increments at zero altitude above ground (defined as the airplane resting on the compressed landing gear). values obtained for a flap position of $40^{\circ}$ are shown in Figs. 7 and 8 as functions of lift coefficient. It can be seen that most of the flight data were obtained at a lift coefficient of about 1.1, which is representative of the expected CID/720 condition on the approach to impact. Similar data obtained from the literature search are included for comparison. Recommended models and uncertainty bounds are shown for each coefficient in the region of interest. These were based largely on the most recent flight results for lift and pitching moment.

Figure 7 shows reasonable correlation in the pitching moment data. Because of the quality of the flight data in this axis, the uncertainty bounds are small.

The two CID/720 lift increment measurements at $40^{\circ}$ flap show close agreement (see Fig. 8). On the other hand, these values are considerably larger than most of the other data sources. One notable exception is the Convair 990 data, also obtained from flight, which tends to confirm these larger values. Limited $C I D / 720$ data at $50^{\circ}$ flap position (not shown) also indicates larger values of lift increment.

Since no useful drag data were obtained from flight, the results of only the literature search 
are shown in Fig. 9. Considerable variations exist in these values. The recommended model was determined as a coarse average of these results and the dispersion was used to determine the uncertainty level.

The variation of these increments as a function of altitude is shown in Fig. 10. These data were obtained from several sources and generally show good agreement.

\section{Simulator Results}

Simulator runs without a ground-effect model and with the recommended ground-effect model were made. The resulting changes in longitudinal touchdown point, vertical speed, pitch altitude, and airspeed are summarized on Table 2 .

The ground-effect lift increment was varied by a gain factor to determine the sensitivity of the airplane response to the increment. The change in touchdown point because of this variation is shown in Fig. 11. The uncertainty bounds for the lift increment model are also shown on this figure.

The ground-effect lift, pitch, and drag increments were then varied simultaneously. The extreme combinations of uncertainty were combined for these tests. For example, the "short" case consisted of the least expected increase in lift, the most increase in nosedown pitching moment, and the least decrease in drag. The senses were reversed for the "long" case. The incremental changes in the simulated response to these extreme combinations are shown in Table 3 . It should be noted that variations of the flight control system (such as feedback loop gains) or the approach flightpath will affect these results. Although the final CID configuration may not be represented in this study, the results illustrate the importance of the ground-effect model.

\section{Concluding Remarks}

A groundmeffect analysis of a jet transport airplane using data from various sources has been made. Flight testing was conducted to measure ground-effect pitching moment and lift increments. Constant angle-of-attack approach maneuvers provided useful data whenever calm atmospheric conditions were present. Although less practical, level passes were also used to measure groundeffect pitching moment increments. Ground-effect drag increments were not successfully measured in flight. The results were correlated with data from previous wind tunnel studies, analytical techniques and flight tests with a similar vehicle. A good comparison was observed for pitching moment data. The lift increments measured in these tests were consistent, but were generally larger than the values obtained from nonflight prediction techniques. Other flight results for a similar aircraft tended to substantiate the current flight results.

The recommended model of ground effect from this study was implemented in a ground-based simulator. Typical response of the airplane to this model, and the sensitivity of the response to uncertainty in this model were shown.

\section{References}

${ }^{1}$ Snyder, C. Thomas, Drinkwater, Fred J. III, and Jones, A. David, "A Piloted Simulator Investigation of Ground Effect on the Landing Maneuver of a Large, Tailless, Delta-Wing Airplane," NASA TN D-6046, 1970 .

${ }^{2}$ Taylor, Albert E., "Evaluation of Take-off and Landing Facility," Tech. Memo. FTFF-TM-58-12, U.S. Air Force Fligt Test Center, Apr. 1958.

${ }^{3}$ Baker, Paul A., Schweikhard, William G., and Young, William R., "Flight Evaluation of Ground Effect on Several Low-Aspect-Ratio Airplanes," NASA TN D-6053, 1970.

${ }^{4}$ Schweikhard, William, "A Method for In-Flight Measurement of Ground Effect on Fixed-Wing Aircraft," J. Aircraft, vol. 4, no. 2, Mar.-Apr. 1967, pp. 101-104.

5 "Aerodynamic Data for the 707 Flight Simulator," Boeing Document No. D6-1154., 1953, Figs. II-A.9, II-B.4, II-B.4.1, and II-C. 10 .

6 "USAF Stability and Control DATCOM," Air Force Flight Dynamics Laboratory, Oct. 1960. (Revised Jan. 1974.)

7Woodward, Frank A., "Analysis and Design of Wing-Body Combinations at Subsonic and supersonic Speed," J. Aircraft, vol. 5, no. 6, Nov.-Dec. 1968, pp. 528-534.

${ }^{8}$ Buda11, Michael R., "Force Test of TC-170E-34 Model with "Stub" Horizontal stabilizer," Univ. of Washington Aeronaut. Lab. Report No. 755.

${ }^{9}$ Vogler, Raymond D., "Investigation over Moving Ground Plane of a Transport Airplane Model Using Blowing Over Flaps for Boundary-Layer Control," NASA TN D-4083, 1967. 
Table 1 Geometric properties of configurations

\begin{tabular}{|c|c|c|c|c|}
\hline Configuration & $\begin{array}{c}\text { Span } \\
m \quad(f t)\end{array}$ & $m^{2}\left(f t^{2}\right)$ & $\begin{array}{c}\text { Mean aero- } \\
\text { dynamic chord, } \\
m(f t)\end{array}$ & $\begin{array}{l}\text { Sweep, } \\
\text { deg }\end{array}$ \\
\hline $\begin{array}{c}\mathrm{KC}-135 \text { and } \\
\mathrm{CID} / 720\end{array}$ & $39.880(130.83)$ & $226(2433)$ & $6.14(20.2)$ & $\begin{array}{l}35 \text { at } 0.25- \\
\text { percent chord }\end{array}$ \\
\hline $\begin{array}{l}\text { wind tunnel } \\
\text { model }\end{array}$ & $2.695(8.84)$ & $1.212(13)$ & $0.4155(1.4)$ & $\begin{array}{l}35 \text { at } 0.25 \text { - } \\
\text { percent chord }\end{array}$ \\
\hline Convair 990 & $36.580(120.00)$ & $209(2250)$ & $6.34(20.8)$ & $\begin{array}{l}35 \text { at } 0.25- \\
\text { percent chord }\end{array}$ \\
\hline
\end{tabular}

Table 2 Simulated airplane response to recommended ground-effect model.

\begin{tabular}{lcc}
\hline Touchdown parameters & $\begin{array}{c}\text { Incremental change } \\
\text { (recommended model - no model) }\end{array}$ \\
\cline { 2 - 3 } & Autotrack on & Autotrack off \\
\hline $\begin{array}{l}\text { Touchdown point, m (ft) } \\
\text { vertical speed (positive } \\
\text { up), m/sec (ft/sec) }\end{array}$ & $0.40(1.3)$ & $0.61(26.0)$ \\
$\begin{array}{l}\text { Pitch attitude, deg } \\
\text { Airspeed, m/sec (ft/sec) }\end{array}$ & $0.61(2.0)$ & -1.4 \\
\hline
\end{tabular}

Table 3 Variation in simulator response to uncertainty bounds

\begin{tabular}{|c|c|c|c|c|}
\hline \multirow[t]{2}{*}{ Touchdown parameters } & \multicolumn{2}{|c|}{ Autotrack on } & \multicolumn{2}{|c|}{ Autotrack off } \\
\hline & short & Long & Short & Long \\
\hline $\begin{array}{l}\text { Touchdown point, } m \text { (ft) } \\
\text { Vertical speed (positive up), } \\
\text { m/sec (ft/sec) }\end{array}$ & $\begin{array}{ll}-9.1 & (-30) \\
-0.49 & (-1.6)\end{array}$ & $\begin{array}{ll}14.0 & (47) \\
0.43 & (1.4)\end{array}$ & $\begin{array}{ll}-20.0 & (-66) \\
-0.73 & (-2.4)\end{array}$ & $\begin{array}{l}20.0(66) \\
0.73(2.4)\end{array}$ \\
\hline $\begin{array}{l}\text { Pitch attitude, deg } \\
\text { Airspeed, m/sec (ft/sec) }\end{array}$ & $\begin{array}{c}0.10 \\
-0.30(-1.0)\end{array}$ & $\begin{array}{c}-0.10 \\
0.40(1.3)\end{array}$ & $\begin{array}{l}-0.22 \\
-0.30(-1.0)\end{array}$ & $\begin{array}{c}0.25 \\
0.37(1.2)\end{array}$ \\
\hline
\end{tabular}




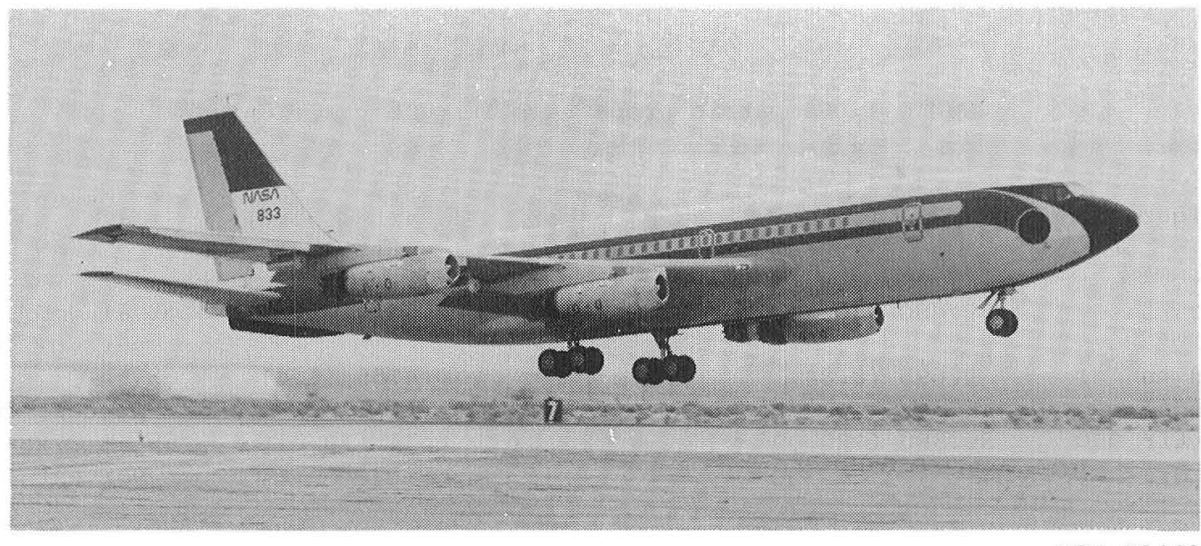

ECN 28448

Fig. 1 Boeing-720 controlled impact demonstration (CID) test aircraft.

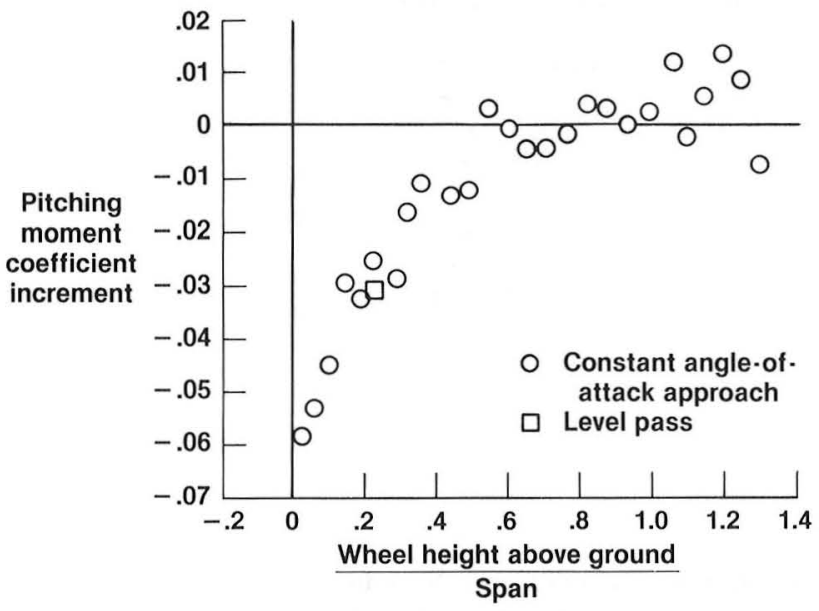

Fig. 2 Ground-effect pitching moment coefficient increment; $K C-135$ aircraft at $50^{\circ}$ flap.

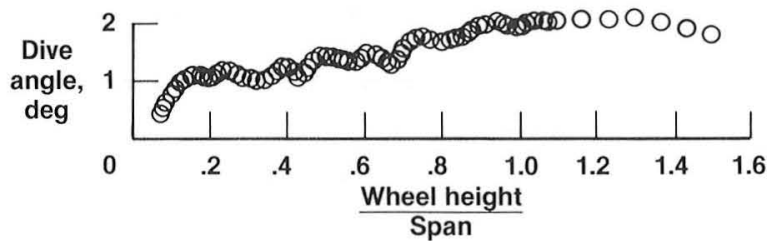

(a) Approach with unsteady winds.

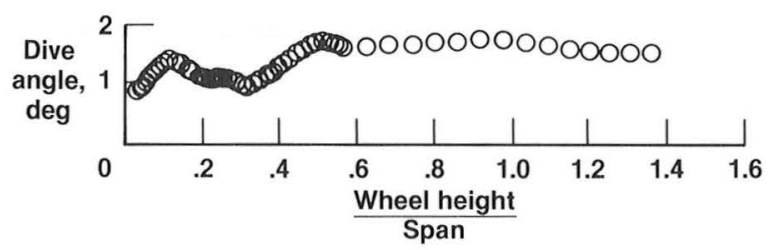

(b) Aproach with gust.

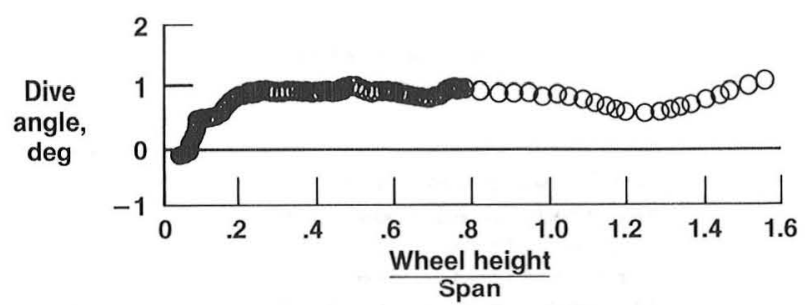

(c) Satisfactory approach for analysis.

Fig. 3 Examples of dive angle variation during approach. 


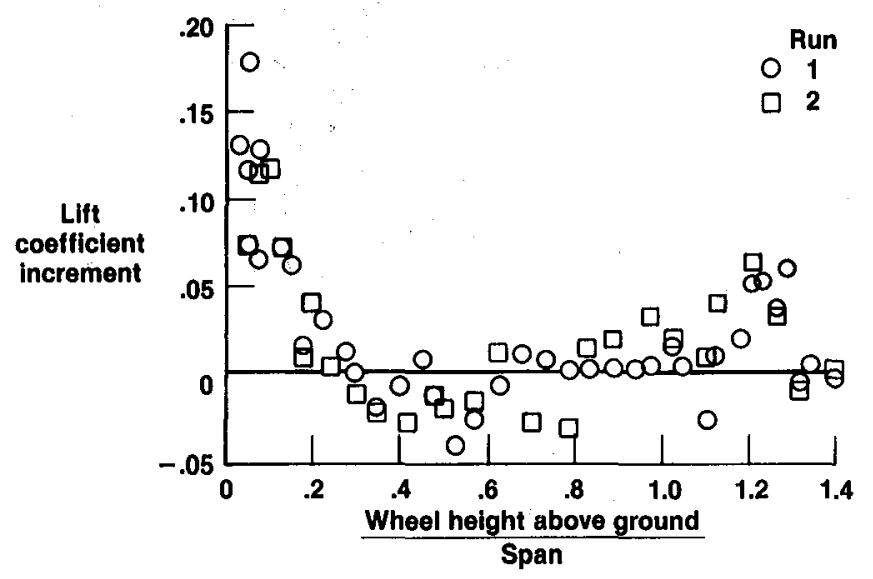

Fig. 4 Ground-effect lift coefficient increment; CID $/ 720$ at $40^{\circ}$ flap.
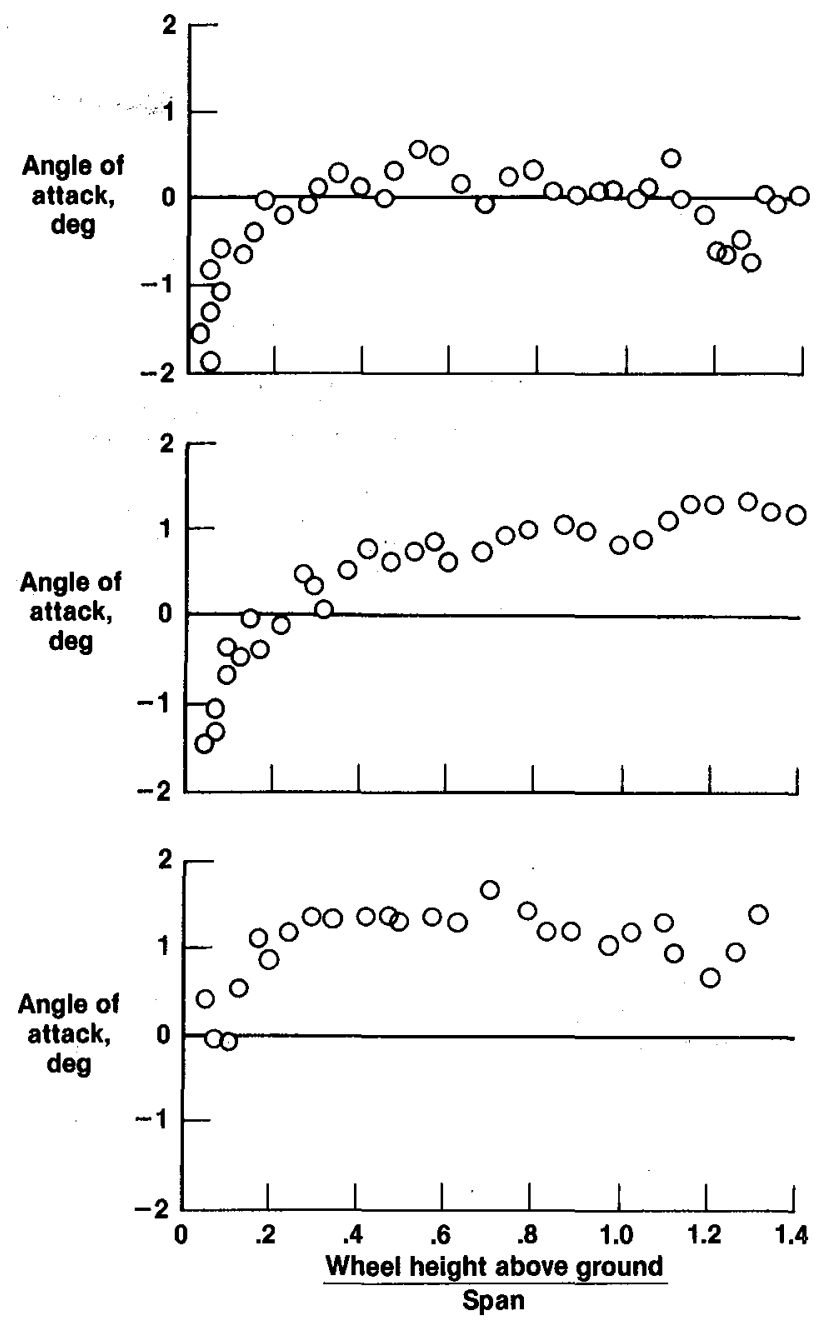

Fig. 5 Angle-of-attack profiles during various approaches.

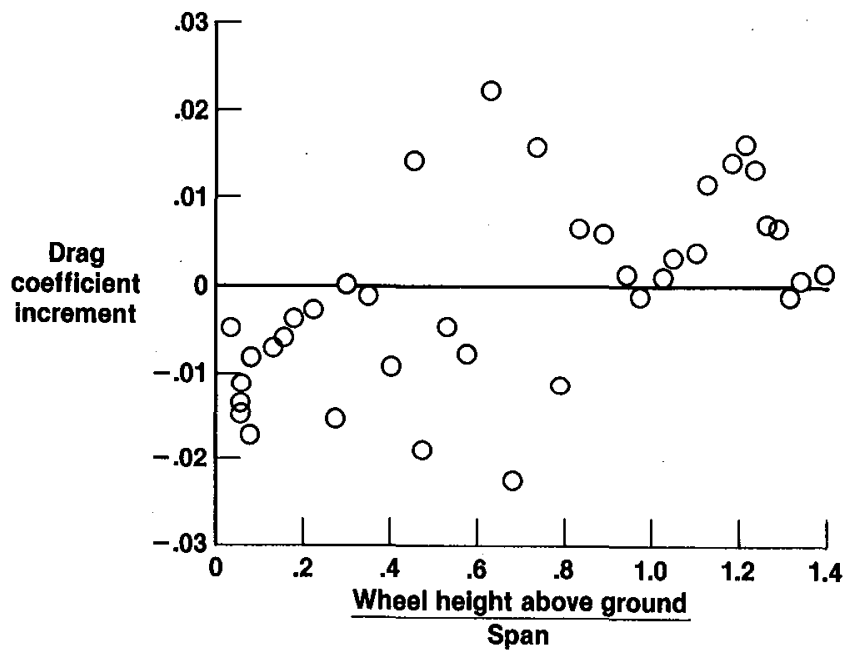

Fig. 6 Ground-effect drag coefficient increment; CID $/ 720$ at $40^{\circ}$ flap. 


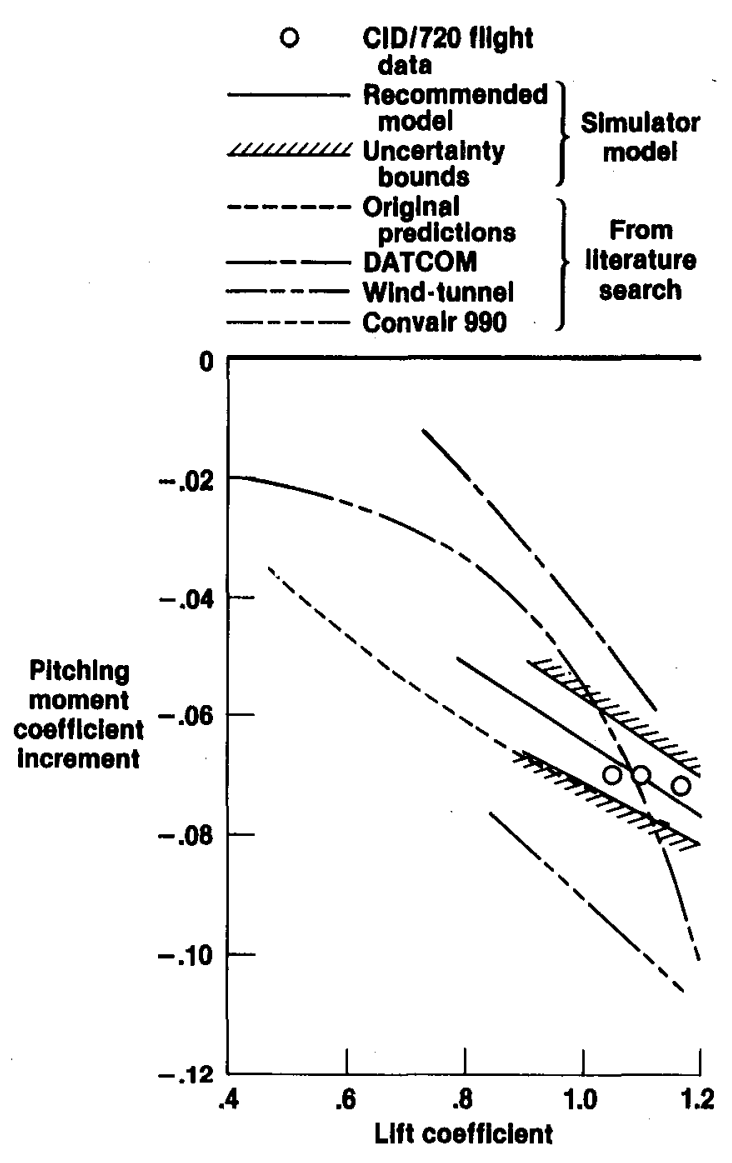

Fig. 7 Ground-effect pitching moment coefficient increment at ground level, $40^{\circ}$ flap.

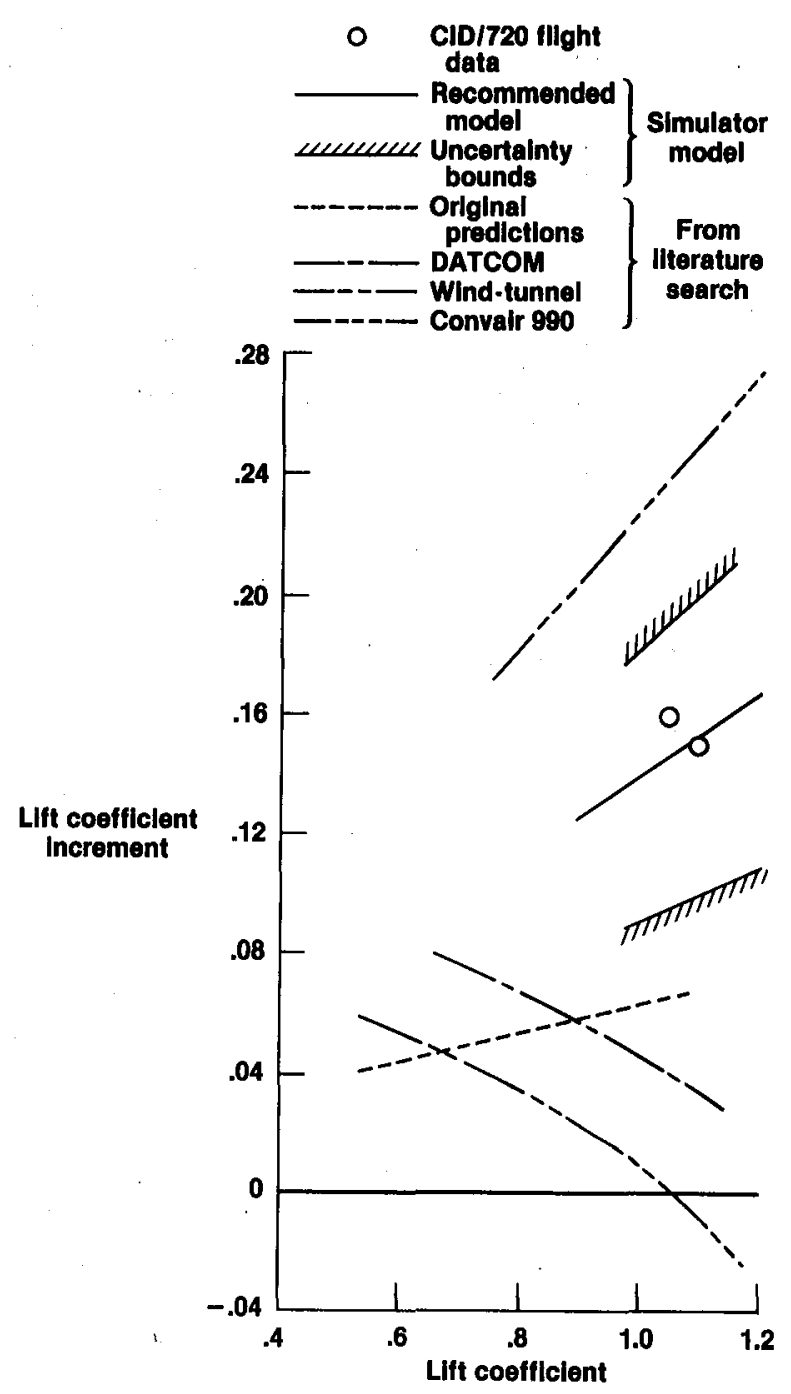

Fig. 8 Ground-effect lift coefficient increment at ground level, $40^{\circ}$ flap. 

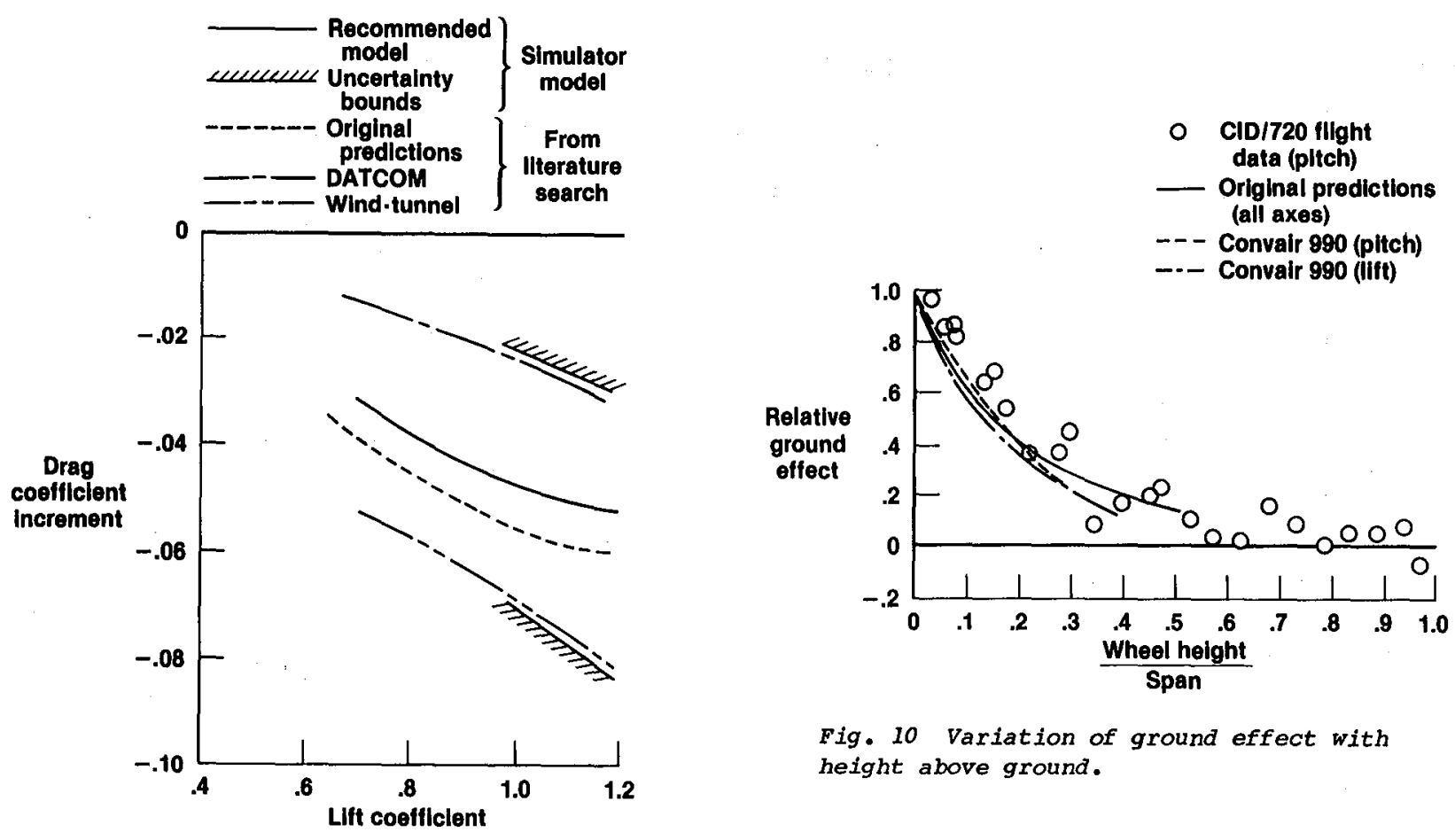

Fig. 10 Variation of ground effect with height above ground.

Fig. 9 Ground-effect drag coefficient increment at ground level, $40^{\circ}$ flap.

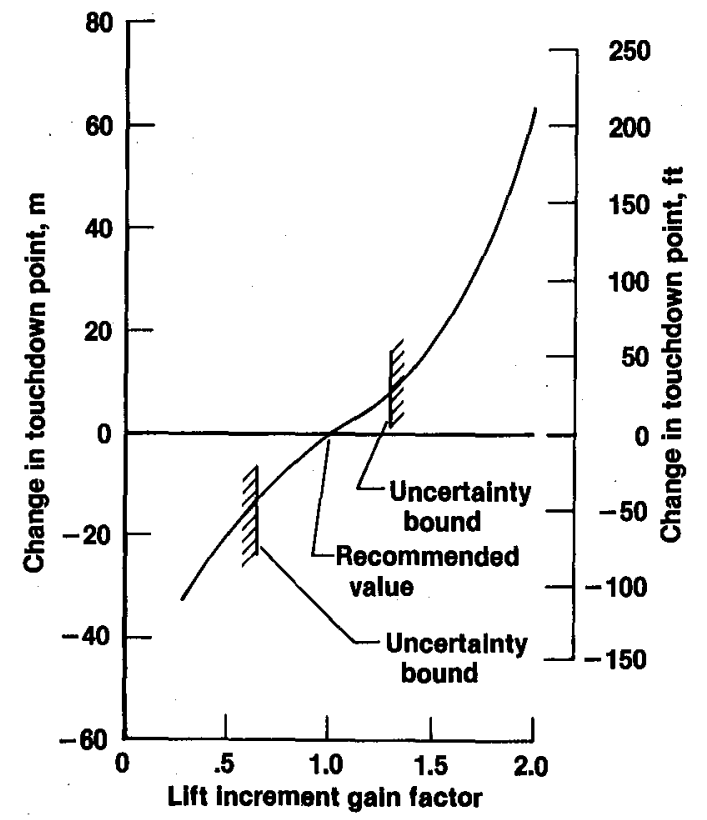

Fig. 11 simulator data showing sensitivity of touchdown point to varidtion of the ground-effect lift increment with auto-track off. 


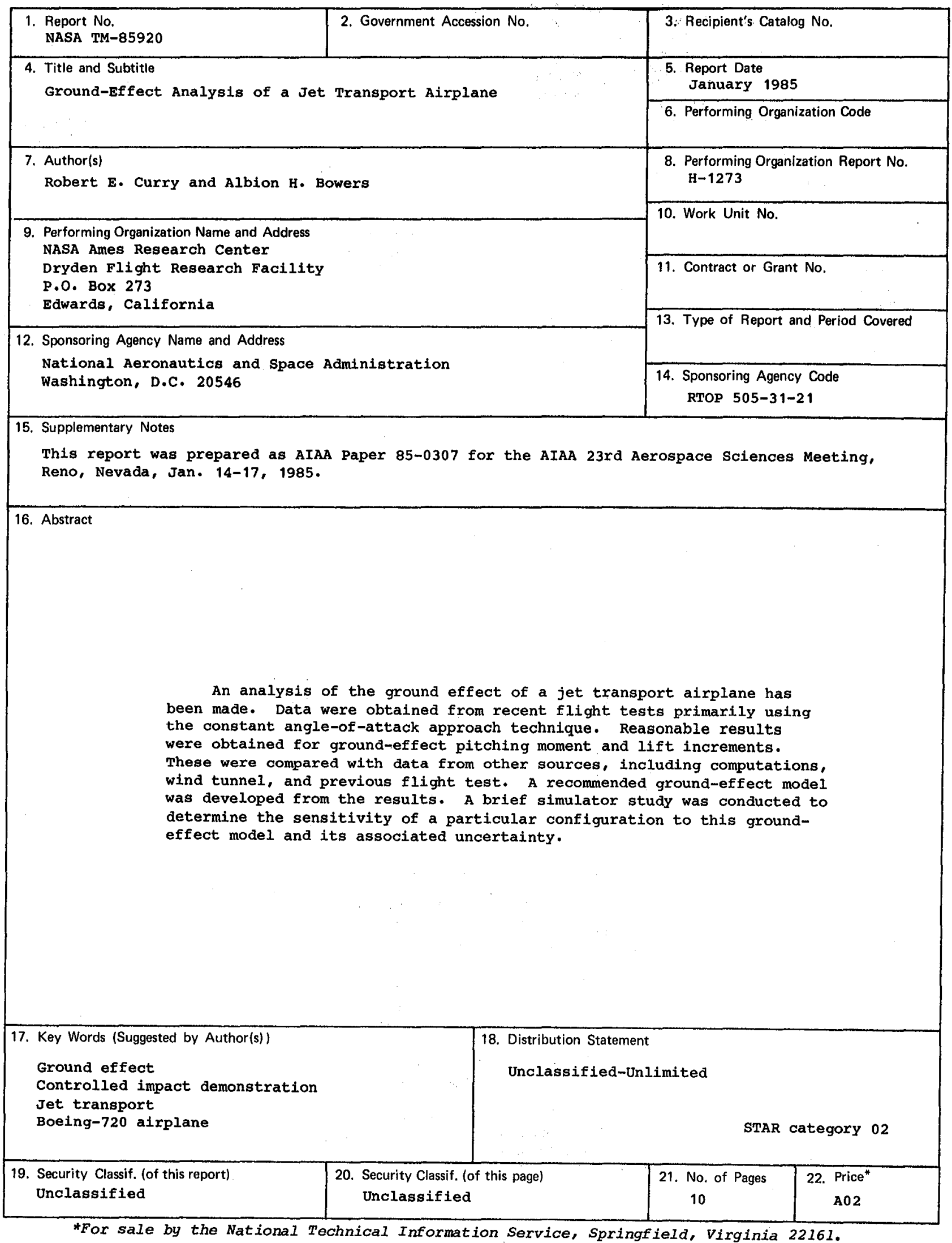


$n$ 